Summer 8-24-2020

\title{
Occupational Therapy's Role in Assisting with Community Reintegration for Survivors of Human Trafficking
}

Jane Jany Huynh

University of St. Augustine for Health Sciences

DOI: https://doi.org/10.46409/sr.ARNT3930

Follow this and additional works at: https://soar.usa.edu/capstones

Part of the Counseling Psychology Commons, and the Occupational Therapy Commons

\section{Recommended Citation}

Huynh, J. (2020). Occupational Therapy's Role in Assisting with Community Reintegration for Survivors of Human Trafficking. [Doctoral project, University of St Augustine for Health Sciences]. SOAR @ USA:

Student Capstone Projects Collection. https://doi.org/10.46409/sr.ARNT3930

This Capstone is brought to you for free and open access by the Student Research at SOAR @ USA. It has been accepted for inclusion in Student Capstone Projects by an authorized administrator of SOAR @ USA. For more information, please contact soar@usa.edu, erobinson@usa.edu. 


\title{
Occupational Therapy's Role in Assisting with Community Reintegration for Survivors of Human Trafficking
}

\author{
Jane Jany Huynh \\ Department of Occupational Therapy, University of St. Augustine for Health Sciences
}

\author{
A Capstone Presented in Partial Fulfillment \\ of the Requirement for the Degree of \\ DOCTOR OF OCCUPATIONAL THERAPY \\ University of St. Augustine for Health Sciences
}

September, 2020 


\title{
Occupational Therapy's Role in Assisting with Community Reintegration for Survivors of Human Trafficking
}

\author{
Jane Jany Huynh \\ Department of Occupational Therapy, University of St. Augustine for Health Sciences \\ has been approved
}

September, 2020

APPROVED:

Susan MacDermott, OTD, OTR/L, Doctoral Coordinator

Becki Cohill, OTD, OTR/L, Doctoral Coordinator

Erin Schwier, EdD, OTD, OTR/L, Program Director

ACCEPTED AND SIGNED:

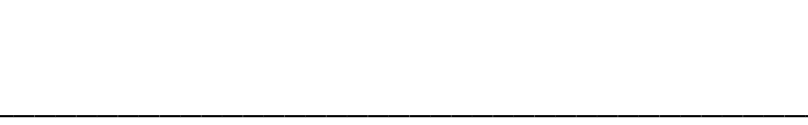

Susan MacDermott, OTD, OTR/L, Doctoral Coordinator

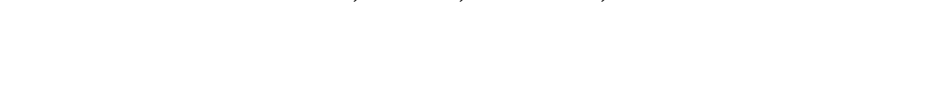

Becki Cohill, OTD, OTR/L, Doctoral Coordinator

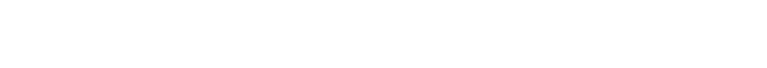

Erin Schwier, EdD, OTD, OTR/L, Program Director 


\section{Table of Contents}

Chapter 1: Introduction............................................................

Background..............................................................

Statement of the Problem......................................................... 8

Purpose Statement..........................................................

Rationale........................................................................ 9

Ecology of Human Performance...............................................

Model of Human Occupation.................................................. 9

Occupational Identity...................................................10

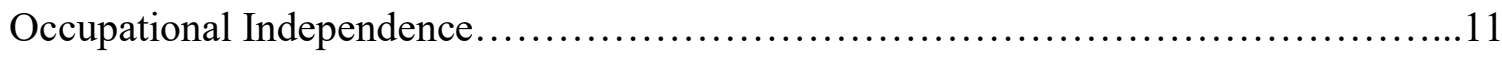

Significance............................................................... 11

Objectives.................................................................

Definitions of Terms........................................................ 12

Assumptions, Limitations, and Delimitations....................................... 14

Chapter 2: Literature Review..................................................... 16

Consequences of Human Trafficking........................................... 16

Trauma-Informed Care....................................................... 18

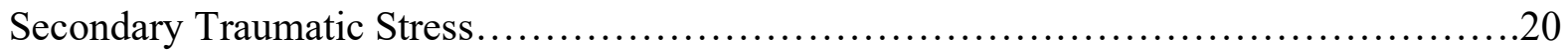

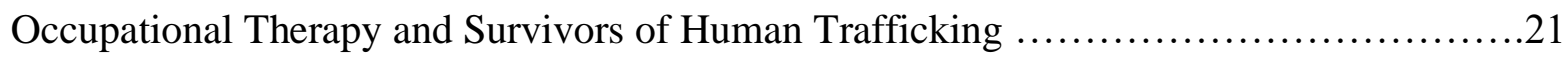

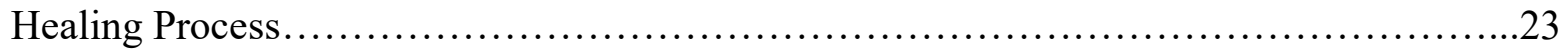

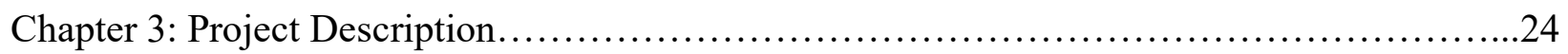

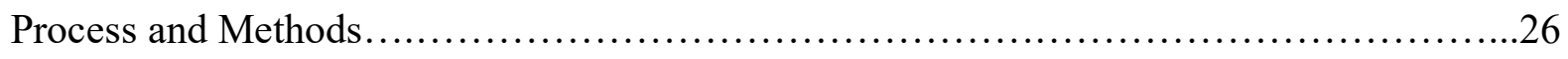

Participants................................................................ 26 


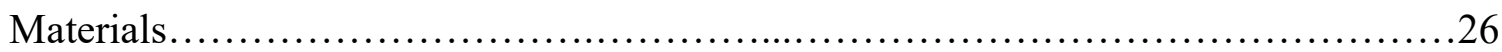

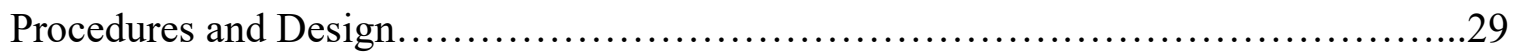

Chapter 4: Results and Analysis................................................. 30

Chapter 5: Summary, Discussion, and Conclusion....................................... 34

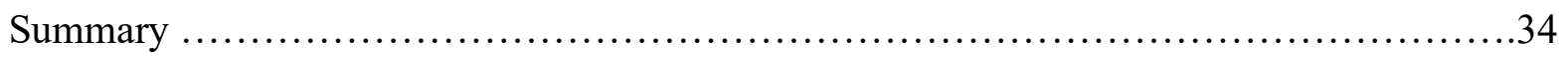

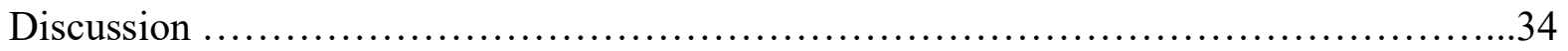

Implications for Occupational Therapy..................................... 35

Conclusion................................................................ 36

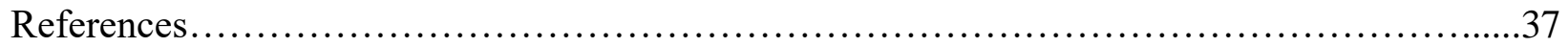

Appendix A - Quality of Life Scale .............................................44

Appendix B - Deliverables for Staff........................................... 45

Appendix C - Deliverables for Clients .............................................48

Appendix D - Logic Model.......................................................... 55 
Copyright @ Jane Jany Huynh, 2020 all rights reserved 


\section{Occupational Therapy's Role in Assisting with Community Reintegration for Survivors of Human Trafficking}

Chapter 1: Introduction

The purpose of this proposal is to investigate the needs of survivors of human trafficking during their transition to community reintegration, and implement a program to assist them through their achievement of occupation-based goals. The proposal outlines the vision for a capstone project that addresses the needs of survivors of human trafficking to enhance community reintegration while utilizing trauma-informed occupation-based interventions.

\section{Background}

Human trafficking is estimated to be the second largest criminal industry, bringing in 150 billion US dollars of profit per year worldwide (International Labour Organization [ILO], 2014a). Within human trafficking, roughly 4.5 million people are sexually exploited, and $98 \%$ of these sexually trafficked victims are girls (Macias Konstantopoulos et al., 2013). The exact statistics of this industry are difficult to estimate due to the underground nature of the exploitation, making it hard for criminal justice authorities to keep an accurate record of cases (Goodey, 2004). Many services and organizations have a hard time keeping track of the need for help due to the underground nature of human trafficking. Because there is a lack of awareness, there is a greater need for help for the survivors of human trafficking to reintegrate themselves into society as they combat social barriers and stigma (Sukach et al., 2018). Some physical and psychological problems of the victims include weight loss, fatigue, musculoskeletal problems, vision loss, fractures, dermatological problems, sexually transmitted diseases, anxiety, depression, post-traumatic stress disorder, suicidal ideation, insomnia, memory problems, social withdrawal, and loss of personal initiative and autonomy, (Cerny, 2016; Gorman \& Hatkevich, 
2016; Macias Konstantopoulos et al., 2013). The area of need is around-the-clock access to trauma-informed (Levin, 2017), client-centered, and evidence-based care to support the emotional, social, and physical well-being of this population (Cerny, 2016).

Occupational therapy has a role of facilitating the client's achievement of participation and engagement in occupation while maintaining or achieving health and well-being (American Occupational Therapy Association [AOTA], 2014-a). This role consists of supporting a client's ability to participate in occupations that are meaningful and purposeful to the client while addressing the client factors, contexts, environment, physical abilities, performance skills, and performance patterns. Occupational therapy interventions include focusing on the specific type of occupations or activities, education, training, advocacy, self-advocacy, and group interventions (AOTA, 2014-a). The AOTA adopted the Vision 2025 that communicates the core tenets and development of the field including making the services accessible to different cultures and customs, collaborating with the clients and between systems, utilizing evidence-based and cost-effective practices, and creating leaders who assert their influence over policies, environments, and complex systems for the betterment of occupational therapy and the clients (AOTA, 2017). Occupational therapists have been pushing traditional boundaries to achieve occupational justice for the clients as an emerging area; this includes viewing the world and clients with the lens of social justice and understanding the barriers to achieving occupational goals (Paul-Ward, 2009). As the survivors of human trafficking face the unique barriers of physical, emotional, psychological, financial, and environmental barriers to their recovery, they face many challenges that interfere with their reintegration into society with occupational achievements that give them meaning and purpose. The field of occupational therapy can facilitate and assist survivors of human trafficking as they reintegrate into society through 
occupational advocacy, training, education, activities, and group interventions. Occupational therapy has a powerful role as these survivors are transitioning from an environment where they were deprived from meaningful occupations and lacked autonomy to an environment where they can reintegrate into society and achieve occupational independence (Cerny, 2016).

\section{Statement of the Problem}

Human trafficking negatively impacts the survivors' physical, psychological, cognitive, and social health, which affects their ability to reintegrate back into society. The complex trauma that the survivors faced has occupational impact due to the consequences and their response to their traumatic experiences. Occupational therapy can assist with their transition back to society through client-centered, holistic care that focuses on occupational justice and enhancing opportunities for occupational participation for the survivors (Cerny, 2016). The survivors of human trafficking face the issue of occupational injustice due to exploitation and coercion. As they were forced into servitude and had no meaningful occupation, they face health risks and lack of autonomy, which can affect their activities of daily living as well as their occupational justice (George \& Stanley, 2018). The purpose of this capstone is to explore the priorities of clients and address the ecology that impacts their transition to community reintegration, as this area is still under-researched.

\section{Purpose Statement}

The purpose of this project is to develop a program that assists the survivors of human trafficking to successfully reintegrate into society through the participation of meaningful occupations, which empowers the survivors to embrace their opportunities, promote autonomy, and provides them access and education to perform occupational tasks independently. 


\section{Rationale}

\section{Ecology of Human Performance}

This capstone project intends to meet the needs of the survivors of human trafficking to enable them to reintegrate into society. The Ecology of Human Performance (EHP) occupational therapy model describes ecology as the interaction between individuals and their environment (Dunn et al., 1994). With EHP, the intervention approaches will include developing the role and occupations of the person based on the interactions of their talents and abilities with their experiences (Ramafikeng, 2011). The model's focus on the interdependent relationship between a person and their environment expands to the aspects of physical, temporal, social, and cultural (Dunn et al., 1994). The survivors' roles will need to be restored or established, and the tasks associated with their roles will need to be altered or created as they reintegrate into society (Ramafikeng, 2011). Some examples of the restorative areas for survivors can include, but are not limited to, personal initiative and autonomy for education, activities of daily living (ADLs), money management (Cerny, 2016), finding housing, and employment (Thompson, 2017). Using the EHP model, the survivors' roles and occupations will be interdependent with many factors, including where they live during survivorship, the people in their surroundings, the cultural practices and routines in which they have been accustomed to, and the resources they are exposed to. The needs of the survivors must be understood under this model so that the survivors are seen through an occupational therapy lens that fully considers all the needs of the survivors and the impact that the environments may have on survivors' recovery and reintegration.

\section{Model of Human Occupation}

The Model of Human Occupation (MOHO) guides the occupational therapy role with this population because it is essential to understand the survivors' needs through their volition, 
habituation, and performance capacity in order to facilitate their process of reintegration into the community (Kielhofner, 2008). While MOHO is client-centered, it is an occupation-focused model that emphasizes the impacts of occupation, including motivation, patterns of behavior, skilled performance, and influence of environment (Kielhofner, 2008). Occupational therapy functions with the lens that practitioners design occupation-based interventions to enable participation and engagement with the environment (AOTA, 2014-b). Through occupational therapy facilitation, survivors will reintegrate into the community and engage with their environment through access to occupational tasks and freedom under MOHO, which will be modified to meet each client's individual volition, habituation, and performance capacity. Survivors will experience occupational justice by addressing the barriers to the occupational freedom and goals. Thus, the survivors will be facilitated by practitioners using MOHO to identify the areas of impact to their occupational tasks and addressing the needs to achieve their performance.

\section{Occupational Identity}

How occupation contributes to identity has been studied by different scholars. Christiansen (1999) suggested that occupation contributes to the construction of one's identity through the interpretation of actions, our relationship with others, contribution to meaning of everyday events and life itself, as well as its promotion in well-being and life satisfaction. During their experience of being trafficked, the victims were identified by their environment of abuse and lack of freedom (Sukach et al., 2018), which formed their "occupational identity" in the sense that occupational identity can be formed through the interactions of the individual and their social dimensions (Phelan \& Kinsella, 2009). Thus, the survivors' lack of freedom during the time they were trafficked contributed to their limited occupational identity, which can change as 
they transition to an environment with occupational independence. Occupational therapists can assist survivors in their process of transition from having no freedom for occupational identity to living in a society in which they can build their own goals for occupational tasks and selfinitiation.

\section{Occupational Independence}

Occupational independence is a focus for occupational therapy in such that independence leads to increased quality of life. Fostering independence is important as it builds selfconfidence, decreases the workload for caregivers, and prevents learned helplessness (Connor, 2019). Independence as a focus in occupational therapy has shifted from "physical self-reliance to client self-determination or autonomy" due to the disability rights movements in western societies (Russell et al., 2002). This shift molds the focus of independence for the population of survivors of human trafficking, as they faced occupational independence and total control of their freedom during captivity as a victim (Gorman \& Hatkevich, 2016; Sukach et al., 2018). Occupational therapists can emphasize the interaction between the persons and their environment, and to empower and educate the survivors so that the survivors can make their own choices and direct their own care, which leads to independent decision making as they reintegrate into their society (Russell et al., 2002).

\section{Significance}

This proposed project is significant to enable the reintegration of survivors of human trafficking so that they may have increased quality of life as they adjust to their environment and society. The project seeks to facilitate reintegration into society through the client-centered practice and trauma-informed care that addresses the needs of medical, physical, cognitive, emotional, and occupational needs. 


\section{Objectives}

- Conduct a needs assessment to gather understanding the occupational needs and personal, occupational goals of survivors of human trafficking within a community human trafficking organization through the modified-Canadian Occupational Performance Measure (modified-COPM) and interviews with participants, staff, and volunteers

- Build rapport and trust with survivors of human trafficking within the community human trafficking organization to ensure accurate understanding of occupational needs, goals, and barriers

- Analyze data to determine occupational barriers the survivors are facing to reach occupational independence and achievement

- Assess a developed occupational-based program to assist with implementation and refinement to improve sustainability and continuity within the program

- Participate in occupation-based programming to gain a hands-on understanding of the progress of the program, and provide enhancements and recommendations throughout with overseeing case manager

- Identify continued tasks for the role of occupational therapists and future staff to assist the survivors of human trafficking within the community human trafficking organization so that occupation-based community reintegration remains a priority

\section{Definition of Terms}

Human Trafficking is defined by the United Nations Office on Drugs and Crime (UNODC) (2015) as exploitation of a person(s) through means of being threatened or forced (with use of "coercion, abduction, fraud, deception, abuse of power" [p. 5]) and being recruited, transported, transferred or harboring for the benefit of achieving control over another person. 
Human trafficking encompasses sex trafficking, labor trafficking, forced child labor including child soldiering, debt bondage, and involuntary domestic servitude (Gorman \& Hatkevich, 2016; Sukach et al., 2018).

Sex trafficking is the exploitation of a person(s) through means of being threatened or forced to perform sexual acts and to suffer violence such as rape, beatings, torture, and imprisonment, physical and emotional abuse, and sold for sex by their traffickers (HardingJones, 2019). It has been suggested that $19.3 \%$ of global trafficked victims (ILO, 2014b) and 77.6\% of the U.S. trafficked victims (Polaris, 2019) are forced into sexual exploitation.

Labor trafficking is the modern-day slavery in which a person(s) is being forced to perform labor or services through violence, fraud, or coercion. Examples of common types of labor trafficking include domestic servants or farm workers (National Human Trafficking Hotline, n.d.). Labor trafficking exists among $61.8 \%$ of global trafficked victims (ILO, 2017) and $17 \%$ of the U.S. trafficked victims (Polaris, 2019).

The term victim in this topic is used as people who has been subjected to the violence of trafficking or is being trafficked. This term does not imply weakness, guilt, or blame (Rape, Abuse \& Incest National Network [RAINN], Alexenko, Satinsky, \& Simmons, n.d.). Within the criminal justice system, the term victim serves as a "status that provides certain rights under the law" (p. 1). Community responses and the legal process predominantly use the term victim (RAINN et al., n.d.).

The term survivor is used with the connotation of empowerment to convey the initiation of the healing process and the possibility of gaining some sense of peace. Community-based advocates are more likely to use the term survivor, as well as practitioners and individuals working with this population (RAINN et al., n.d.). 
Occupational justice is the belief that a person has the right to engage in meaningful occupations to meet his or her individual needs and potential. Literature represents occupational injustice as having barriers that inhibit engagement in meaningful occupation (Durocher et al., 2013).

\section{Assumptions, Limitations, and Delimitations}

Assumptions of this capstone project include that the survivors at the community human trafficking organization value community reintegration, have occupational difficulties with community reintegration, and prioritize reintegration to participate in occupation-based programming. The participants need to identify their needs and barriers to community reintegration during the needs assessment and interview. If they do not value the need for occupation-based reintegration, they may choose to withdraw from the program. The project assumes that the participants are ready to participate in the different processes of community reintegration. However, each participant's process of recovery is individualized, and some participants may require unforeseeable program modifications.

Limitations of this capstone project include the location, financial resources, language barrier, time-constraints, and the beginning of a pandemic. This project is limited by the location of the community human trafficking organization and the participants who reside in the safehouses contracted with the organization. The project cannot venture too far or utilize resources of farther distance due to limited transportation options for the participants. Another limitation is limited financial resources as the participants pursuing occupation-based tasks for community reintegration must be able to modify or establish attainable goals with low funding. Additionally, language barrier poses a limitation as some clients do not speak English, which may create an obstacle for their interaction with the program and with their environment as they 
attempt to reach their goals. The time-constraint of the project is a limitation due to the timeframe of the capstone project and the timeframe the participants may expect to see results and changes in their life. A special limitation arose during the beginning of this project as the COVID-19 pandemic was underway, changing the environment of the community human trafficking organization, the ways in which the survivors interacted with their environment, and the resources that remained available to them.

Delimitations include the EHP being used guide the development of this capstone project, for it may not be a good fit for the program developed or for the client population served. The EHP framework interconnects the survivors' roles and occupations to their setting, the people in their surroundings, and the cultural practices and routines they've been accustomed to. However, the survivors are undergoing a time of transition and recovery. Therefore, their surroundings and culture may still be developing and molded. This area may or may not require modifications as the project proceed and progress throughout the weeks. MOHO is also a delimitation for this project as all the aspects of OT will not be considered. Following MOHO, the focus of this project includes volition, habituation, and rituals. The student will request for the information through a form of discussion rather than observation, which limits the information gathered from the survivors. The objectives of the capstone project are delimitations as they may be inappropriate or unattainable at the specific site or with this group of participants. The objectives are expected to change throughout the project, modified and refined to accurately intersect the goals of the student as well as the clients served. An additional delimitation includes the process of needs assessment and interviews. While utilizing the modified-COPM to guide conversation, the student intends to keep the process informal to increase rapport building. However, the 
method of conversation may affect the type of information offered by the participants, which affects the overall program development.

\section{Chapter 2: Literature Review}

A literature review includes several themes that justify the need for this capstone project. The areas of study include consequences of human trafficking, trauma-informed care for the survivors, secondary traumatic stress experienced by the caregivers of this population, the role of occupational therapy in human trafficking, and the healing process of the survivors. These areas studied are all inter-connected with the barriers of the survivors of human trafficking and used to guide the development of this program.

\section{Consequences of Human Trafficking}

The consequences of human trafficking are covered in an extensive amount of studies. The survivors suffer from weight loss, fatigue, neurological disorders, gastrointestinal disorders, musculoskeletal illnesses, vision problems, dermatological illnesses, gynecological diseases, dental problems, headaches, chest pain, breathing difficulty, fractures, sprains, insomnia, and HIV and other sexually transmitted diseases (Black, 2007; Cerny, 2016; Gorman \& Hatkevich, 2016; Levine, 2017; Macias Konstantopoulos et al., 2013; Sukach et al., 2018). Mental health concerns, which include PTSD, depression, anxiety, dissociative disorder, substance and drug addiction, dependency on drugs to relieve or cope post-trauma, suicidal ideation, hopelessness. Emotional consequences include that the survivors struggle with shame, humiliation, continuous stress, anger, irritability, self-esteem problems, mistrust of men, poor sleep quality, self-hatred, feelings of despair (Black, 2007; Cerny, 2016; Egger, 2017; Gorman \& Hatkevich, 2016; Levine, 2017; Sukach et al., 2018; Macias Konstantopoulos et al., 2013). The survivors are challenged with many co-morbidities and challenges that create a barrier for them to return to occupational- 
based recovery, for they experience occupational alienation and deprivation due to social withdrawal and loss of personal initiative and autonomy (Cerny, 2016).

A narrative review by Stewart et al. (2019) explored the occupational perspective of women's experiences of life after sexual assault. The study expresses that sexual assault may pose a threat to occupational justice through serious occupational disruptions due to the link between health, well-being, and engagement in life and the society. Devastation occupational impact from the trauma and assault includes self-care, caring for others, work, leisure, and occupational roles and relationships. This study was a type of systematic qualitative review, which focused on longitudinal studies that were 6 months or longer, peer-reviewed research articles, and focused on the experiences of the female survivor. The results displayed that occupations at risk included smoking, use of alcohol and drugs, and more risky sexual behaviors. These behaviors were considered a risk due to the effects on the women's health, well-being, and relationships.

Levine (2017) goes into details about the severe mental diagnosis of survivors, including Disorders of Extreme Stress (DESNOS). The victims also face alcohol and drug abuse as a consequence. The body handles the stress and trauma with biological and neurological changes, affecting brain structure and hormone release which creates a barrier for the recovery of the survivors over time. Levine furthers emphasizes that survivors face social stigmatization and feelings of hopelessness. All the consequences that the survivors face as an aftermath requires an organization of multi-disciplinary healthcare team to treat (Levine, 2017). When trauma is left unaddressed, it may result in health problems and occupational complications. Therefore, it is necessary for occupational therapists to foster a recovery process that utilizes coping techniques 
to help promote engagement and occupational participation while supporting safety and functional performance in the recovery process. (AOTA, 2018).

\section{Trauma-Informed Care}

The need for trauma-informed care originated from the experiences of the survivors when they were experiencing the trauma as victims. The trauma of the victims include freedom rape, threats, beatings, malnutrition, unsanitary environment and contact, lack of medical care, infections, abortions, isolation, being controlled (lack of autonomy), kicked, shot by guns, stabbed by knives, slammed against the wall, burned, hit, punched, pulled by the hair, and other types of injury (Gorman \& Hatkevich, 2016; Sukach et al., 2018). Studies show that the survivors faced unforgettable trauma that requires trauma-informed care by the specialists that they work with during recovery, including emotional support, counseling, shelter-housing, food, and transportation (Egger, 2017; Harriot, 2017). Trauma causes the brain to become overwhelmed and can significantly impair a person's cognitive processing and working memory as it is a part of the body's emotional center. (Morey et al., 2009). A study by Macias Konstantopoulos et al. (2013) suggested that the variety of health workers and community workers train for trauma-informed care to obtain the skills necessary to provide safe interventions. Sensitivity and understanding of the complexity of the physical and psychological trauma of the trafficked survivors were essential to recognizing and addressing the full spectrum of their health and mental needs (Macias Konstantopoulos et al., 2013). The practice of traumainformed care comes with the recognition of the signs and symptoms of the trauma faced by the survivors and the practice of communication without retraumatizing the survivors. Screening and rapport building should be complete in a nonjudgmental manner and validating the survivors during conversations (Adams Hillard, 2019). Constructing a trauma-informed environment 
includes proper staff training, engaging the clients in organizational planning, creating a safe environment, and preventing secondary traumatic stress in staff. It is essential to empower the survivors to make their own choices, collaborate and plan with them, modify comments and the environment so that it does not retrigger their traumatic experiences, and ensure that they feel respected and supported (Menschner \& Maul, 2016).

One of the most important parts of community reintegration for survivors is to address the impact of the trauma they experienced. While survivors may lack effective coping techniques, therapist can assist in positively changing and managing feelings of shame, guilt, and self-worth by allowing survivors to take a lead in the therapy process (Wilson \& Butler, 2014; Oram \& Domoney, 2018). This is especially important as the survivors lacked autonomy and were restricted from making decisions pertaining to individual choices and occupation during their captivity. The trauma and seclusion they faced destroyed their connections to others (Wilson \& Butler, 2014). A holistic approach to trauma-focused cognitive behavioral therapy (TF-CBT) has been found helpful for survivors to develop trust and improvement of overall wellbeing. As many survivors of trafficking had their trust broken, boundaries violated, and their needs ignored, it was therapeutic for them to not only receive TF-CBT but also restore trust in human relationships with staff who were engaging and holistic in their interactions with the survivors (Harding-Jones, 2018). An example of this type of interaction included the therapist's willingness to break traditional boundaries to interact with the survivors outside of therapy time. This allows for the survivors to get a sense of an unconditional positive regard and holistic care, which makes the staff/counselor seem more approachable and deepened the relationship between the therapist and the survivors (Harding-Jones, 2019). 


\section{Secondary Traumatic Stress}

Listening to traumatic stories and working directly with the traumatic reactions displayed by survivors of human trafficking may take an emotional toll on the caregivers, or the professionals working with the survivors. Secondary traumatic stress, also known as caregiver burnout, empathy-based stressed, or compassion fatigue, is experienced with consistent exposure to the tales of extreme human suffering and expressions of fear, helplessness, hopelessness, and horror (Sacheti, 2020; Forsyth, 2016; Kliner \& Stroud 2012; Rauvola et al., 2017). The risks of secondary traumatic stress includes exposure to secondhand trauma (through distressing events or clients' recurrent episodes or reactions to triggers) (Sacheti, 2020; Forsyth, 2016; Kliner \& Stroud, 2012; Rauvola et al., 2017), improper staff training and education, high workload (Kliner \& Stroud, 2012; National Child Traumatic Stress Network, Secondary Traumatic Stress Committee [NCTSN], 2011), lack of personal resources and self-care, and social or organizational isolation (NCTSN, 2011). The staff working with survivors may experience symptoms that include fatigue, sadness, anger, overwhelming feelings of distress, and altered eating habits. Signs include compromise of sleep, cognitive function, physical function, and work efficacy (Kliner \& Stroud, 2012; Sacheti, 2020).

Strategies for prevention of secondary trauma stress includes training and education of staff so that they are aware of the risks of indirect trauma exposure, thus empowering them to find prevention strategies that work for each person individually. Organizational support includes caseload balance, self-care groups in the workplace, accountability buddy system, training (NCTSN, 2011), supportive and reflective supervision, clear guidelines, autonomy, and quality supervision and coworker support through regular discussion of cases, concerns, and social 
interactions (Kliner \& Stroud, 2012). Individual interventions include proper rest, exercise, nutrition, active activities that reduces stress, and seeking counseling (NCTSN, 2011).

\section{Occupational Therapy and Survivors of Human Trafficking}

Occupational therapy can provide interventions for the survivors of human trafficking to support and encourage their confidence and self-awareness by promoting modified tasks or environments (AOTA, 2014-a). The interventions can be strengths-based and facilitate the survivors to recognize their barriers to achieving their goals, then modifying necessary areas to improve engagement in supportive occupation (Ginsberg, 2015).

An occupational therapy capstone project by Martin (2015) focused on providing traumainformed support for adolescents who were trafficked living in a transitional home. The author suggested that trafficked survivors suffering from PTSD may have a hard time with ADLs and IADLs due to overwhelming anxiety and stress. The capstone was organized based on the Person-Environment-Occupation Model of Occupational Performance (PEO) to guide the intersection of human trafficked survivors to the benefits of human trafficking. The "person" of this model correlates to the youth survivors, as individuals who underwent trauma and disruption of critical growth periods. This may have affected their development of abstract thinking skills, executive functioning skills, and cause poor attachment skills due to their lack of autonomy and ability to make their own decisions regarding housing, food, or ADLs during their time trafficked (Perry et al., 1995). The "environment" of PEO correlates to the initial exposure of trauma during the time survivors were trafficked versus the environment of transitional services during their recovery process (Martin, 2015). The "occupation" of the model varied depending on the childhood trauma of the survivors, the exploitation they were exposed to, and the limitations that kept the survivors from performing a variety of occupations including ADLs and IADLs (Martin, 
2015). The interaction of the person, environment, and occupation will cause a person's occupational performance and achievement to fluctuate, as these elements are codependent. Martin (2015) performed an occupational therapy needs assessment and SWOT analysis, results suggested that the youth survivors had a need for leisure occupational tasks and preventative services to support transition into more sustainable and appropriate roles. The capstone developed an art program to allows creative expression and a program manual to educate the service providers (artists) with information on trauma-informed care during interaction with the survivors. The program was structured to focus on "improving selfawareness, emotional regulation, cognition, and executive function” (Martin, 2015, p. 16). The access to leisure provided a safe and supportive environment and occupation for the survivors as they continue their journey in the transition home.

Thompson (2017) developed a six-week community integration group for women survivors of sex trafficking as a form of recovery. This capstone measured components that were occupational-based, including safe housing, stable employment, and vocation-focused education. Guided by the biopsychosocial model, the Person-Environment-Occupation (PEO) model, Erikson's stages of recovery, and the Wellness Action Recovery Plan (WRAP), this study sought to understand the comprehensive deficits of consequences the survivors face and develop recovery plan that was client-centered and occupation-focused for long-term wellness. The program developed was called Community Living Integration Club, which focused on measuring the "engagement in gainful employment outside of trafficking and sexual pursuits, engagement in employment-focused education or training, and attainment of safe house in the community" (Thompson, 2017, p. 39). Results from this capstone includes that the survivors showed improvements in areas of work-related, interpersonal relations, and social/community 
expectations. From the program, the survivors displayed more positive change in work-related and social/community expectations than interpersonal relations, and they verbalized the need for "future community living integration groups to cultivate healthy relationships for work settings and social participation" (Thompson, 2017, p. 56).

Gorman \& Hatkevich (2016) discusses the emerging role of occupational therapy for victims and survivors of human trafficking. The study emphasizes the physical and mental health problems that survivors face, including their need for trauma-informed care. The areas survivors have reported needing assistance include "finding housing, family counseling, legal assistance, financial assistance, formal education, and life and job skills training" (Gorman \& Hatkevich, 2016, p. 7006360010p3). Occupation-related barriers include "self-care, money management, home management, child care, employment, task initiation, use of public transportation. Social participation, and healthy coping and relaxation skills" (Gorman \& Hatkevich, 2016, p. 7006360010p3). As occupational therapy practitioners are qualified to provide trauma informed care, they can assist the recovery process through client-entered intervention that leads to positive change in occupational performance to promote wellness, role competence, satisfaction, and improved quality of life. Occupational therapy is a holistic profession that can assist survivors to engage in meaningful and healthy occupations during rehabilitation (Gorman \& Hatkevich, 2016).

\section{Healing Process}

Experiences of trafficking can lead survivors to hold core beliefs of shame, worthlessness or failure, which require long-term therapeutic input to overcome (Oram \& Domoney, 2018). Survivors of trauma and violence benefit from strategies and interventions that include spirituality, peer support, and informal social support (Lewis et al., 2015). A dissertation by 
Egger (2017) explains that hope and resilience are amongst the characteristics of adaptive psychological coping, encouraging hopeful affect, and personal fulfillment for survivors of trafficking. Hope allows for adaptive problem-solving skills while lower levels of hope are correlated with self-deprecatory thinking, suicidal ideation, depression, anxiety, and decreased goal seeking. Egger's results emphasize that survivors have a desire for meaningful, positive attachments, which affects their overall sense of resilience, hope, and psychological well-being. Resilience and hope were found to have positive correlation with positive self-portrayal, hopeful coping mechanisms, and goal-setting and action-planning. The presence of resilience was noted through positive self-identification and having a sense of clear life purpose and meaning (i.e.

completing school, getting a job, etc.). Interviews revealed that hope were expressed in terms of life changes such as completing college, gaining employment, and becoming financially secure in a profession of desire.

All in all, literature exposes the consequences human trafficking, supports the need for trauma-informed care and occupation-based interventions during the recovery process. This capstone seeks to utilize literature to develop and enhance an occupation-based recovery program for community reintegration.

\section{Chapter 3: Project Description}

Survivors of human trafficking face a variety of challenges during their recovery and transition to community reintegration. The categories of needs from the survivors at the community human trafficking organization include a need for facilitating independent living skills, barriers to leisure and social engagement, and a need to address their behavioral health (Mariano, 2019). Per the previous student's capstone at this human trafficking organization, the survivors reported that some of the top priorities of their different needs are employment 
acquisition, education participation, social participation, a sense of community, and personal relationships (M. Mariano, personal communication, January 22, 2020). Some needs of the staff included program organization, assessment intake reformat, discharge follow-up, and caregiver burn out (M. Mariano, personal communication, January 22, 2020). This capstone project seeks to facilitate the process of community reintegration of the survivors based on their perceived needs through program development and refinement of the current program developed at the human trafficking organization. The participants include the survivors, case managers and other organizational staff members. The process includes the needs assessment, the facilitation of the process of community reintegration through engagement in employment acquisition and education participation, and interactive refinement of the program with current staff to improve sustainability.

The role of occupational therapy includes providing facilitation to engage in occupational-based tasks that are goals of the clients and provides meaning and purpose (AOTA, 2014-a). The objectives of this capstone include building rapport with the clients, gathering an understanding of their occupational needs to enhance their quality of life, developing or enhancing the current program at the human trafficking organization, and improving sustainability to the current program to ensure continuity post-capstone phase. The goals of the program include the facilitation of the survivors' process to increased engagement in employment and/or education, improve personal perceived readiness for community reintegration, and enhance satisfaction of engagement in community events and/or personal relationships. It is essential that readiness for community reintegration and satisfaction of engagement is a self-report rather than observation of the survivors' engagement, as this would 
keep the program client-centered. The program also seeks to facilitate increased peer support amongst the staff to decrease the risks of secondary traumatic stress.

\section{Process/Methods}

\section{Participants}

The participants for the program development were the survivors of human trafficking currently seeking refuge and assistance from the community human trafficking organization, as well as the staff members and volunteers. The survivors were gathered based on their readiness for this program, depending on their process of recovery, their willingness to participate, and the case managers' recommendation. The current program at the human trafficking organization had a variety of participants, some survivors had been involved with the previous capstone project of development. Therefore, it must be acknowledged that each survivor was entering the program at a different stage of recovery, readiness, had different talents and abilities to reach their goals.

Participants of this program included a total of 15 survivors of human trafficking and 7 staff members. Three of the survivors left the program as they relapsed back to their former environment. Three of the survivors spoke only Mandarin, two of the survivors spoke only Spanish. One survivor was expecting a child when she entered the program. Three survivors were waiting on their work permits. Four survivors were current and active students in community college, two survivors were taking English as a Second Language (ESL) courses. All the participants contributed to the informal interview process and various parts of the program development process.

\section{Materials}

This capstone sought to enhance the current program of community reintegration at the community human trafficking organization. Therefore, the manual of occupational programming 
designed by the former capstone project was reviewed. Survey results from the staff members were utilized to enhance current program and develop a new program. The measures used included the modified-COPM during the informal interview with participants to gather information regarding participant needs and priorities, and the Quality of Life Scale (QOLS) for outcome measures of: material and physical well-being; relationships with others; social, community, and civic activities; personal development and fulfillment; and recreation (Riopel, 2019). Both of these measures were used to collect baseline data prior to program development. Informal and nonstandardized outcome measures were also used to gather data due to the nature of rapport building and development of trust within relationships. The interviews with the participants during the needs assessments were casual and conversational, taken place mostly in the clients' home, in the office, on the phone, and through texting depending on the comfort of the client in these settings. The conversations were guided by the modified-COPM for productivity, along with considerations of the EHP model and MOHO. The goals of information gathered included answers to the following questions. Questions were used to vaguely guide the direction of conversation but open-ended to gather perceived important and prioritized concerns of the survivors. The questions were focused on occupation-based categories as discussion progressed:

- How do you participate in your community? In what ways do you engage with the environment around you?

- Are there any things you would like to enjoy but cannot right now, what are the barriers? 
- What are your priorities right now? What are the goals you have set in your life right now? What are the barriers to these goals? What steps have you taken to achieve these goals?

- What tasks are important and purposeful to you on a daily or monthly basis? Are there any barriers to you performing these tasks?

- What are your commitments and values in your daily life pertaining to self-care, productivity, and leisure?

- What routines or roles give you meaning and satisfaction?

Outcome measures included informal discussions with participants to gather the progress of engagement in employment acquisition and education participation, and their satisfaction levels of perceived readiness for community reintegration and personal relationships. These areas of concerns were planned according to the previously developed capstone needs assessment, but another needs assessment was conducted to confirm results with the priorities previously gathered.

The staff of the human trafficking organization were also interviewed to understand the needs of the staff and organization, as well as the perceived needs of the survivors based on the staff's experience and relationship with the survivors. The data gathered were based on the following questions:

- What are the organization's perception of each survivor's personal goals for community reintegration? What are some of the barriers these survivors face?

- What are the goals that the staff members have created for the survivors at this organization in regards for community reintegration? What are the barriers to these goals? In what ways are the goals being reached and progressing? 
- How do the staff members connect with the survivors? How do the staff understand the needs of the survivors and assist them with their needs?

- What changes are needed in this facility for the benefit of the clients' ability to perform their desired occupations and progress in the realm of community reintegration?

\section{Procedures and Design}

The program was developed based on a logic model (see Appendix D), which outlined the proposed methods prior to site visitation. The logic model, along with MOHO, EHP, and the modified-COPM, assisted with the focus of the program throughout the process of development.

The survivors of human trafficking underwent the first step of interviews in a conversational format to build rapport with the student. Data was gathered to understand the survivors' occupation-based goals, barriers, and priorities to increase community reintegration. The student gathered the baseline information of the survivors, including the strengths and barriers of the survivors that supported or hindered their ability to achieve their goals. This information was gathered through interviews with the survivors to ensure that the baseline information was client-focused. Furthermore, the environmental strengths and barriers were gathered from survivors and staff to completely understand the support of the survivor's ecology. Data analysis, explained in the following paragraph, allowed a program plan to be developed and enhanced with the cooperation of the organization's staff members and client responsiveness. The initial step of the needs assessment took four weeks.

Data analysis included identifying themes of the occupation-based needs of the clients from the notes of the interviews. Further analysis through reviewing the QOLS scores. The student reviewed findings with the staff at the human trafficking organizaton to confirm and 
understand organizational barriers to some of the clients' unmet priorities. See Table 1 below for the occupational-based needs and the barriers clients faced during the time of this capstone.

Following data analysis was the program development and implementation of this capstone, which included various one-on-one meetings, group meetings, and deliverables created for the staff and clients of the community human trafficking organization.

\section{Chapter 4: Results and Analysis}

The results of the modified-COPM included the areas of concerns and priorities amongst the survivors as shown in Table 1 below.

Table 1

Priorities of Survivors Collected through Conversations Led by Modified-COPM

Priorities of everyday living

School/education

Vocation/getting a job

Transportation

Getting a driving permit

Getting a driver's license

Health

Access to food Access recreation for physical health

Leisure/active recreation

Fostering healthy relationships
Barriers to achieving these tasks and goals

Understanding the enrollment process

Understanding the process of transferring to a university and course planning

Understanding the education system and resources available to assist students

Not understanding English fluently

Having a work permit/lack of legal status

Knowing how to apply for a job

Not speaking English

Knowing how to fill out a job application

Reduced job openings due to COVID-19

Searching for driving instructors

Reduced resources due to COVID-19

Access to a car for practice

Transportation to grocery stores

Lack of knowledge \& education on healthy diet balance and organization of an exercise routine

Safe public transportation due to COVID-19

Safe transportation due to COVID-19

Lack of current, supportive relationships 
The survivors of labor trafficking were less concerned with their leisure and active recreation compared with the survivors of sex trafficking. Rather, survivors of labor trafficking were much more anxious to work on obtaining a work permit, securing a job, and receiving financial earnings to take care of themselves and their family. They were less concerned about their needs for emotional support during interviews and expressed frustration with the process of achieving financial independence.

The QOLS (See Appendix A) was used to collect baseline data. This list contains the areas rated below satisfaction level by the survivors:

- Material comforts home, food, conveniences, financial security

- Relationships with parents, siblings \& other relatives - communicating, visiting, helping

- Close relationships with spouse or significant other

- Close friends

- Helping and encouraging others, volunteering, giving advice

- Participating in organization and public affairs

- Learning - attending school, improving understanding, getting additional knowledge

- Work - job or income

- Socializing - meeting other people, doing things, parties, etc.

- Participating in active recreation

- Reading, listening to music, or observing entertainment

The staff members of the community human trafficking organization expressed a mixture of concerns for their clients as well as the emotional health of fellow staff members. The staff agreed with their clients that priorities of the survivors were based on achievement of independent with their day-by-day tasks, such as decision-making, job seeking, education 
planning, and fostering healthy relationships. The staff also expressed concerns for the survivors' coping skills and emotional health, as the survivors displayed anxiety during communication and challenging situations. In terms of priorities within the organization, the staff identified the need for modification of the in-take assessment and discharge follow-up process with the clients. Staff at this human trafficking organization repeatedly identified concerns with healthy staff-client relationships and healthy case management routine, as the staff vocalized feelings of being overwhelmed by heavy caseload, exposure to emotional trauma displayed by their clients, and lack of reflection within the organization and peer-support.

Program development consisted of a reflection meeting for the staff of the community human trafficking organization to reduce risk of compassion fatigue, and education and resources to guide clients in areas of vocation, education, physical health, and emotional health. Deliverables were developed included a brochure to guide staff into the reflection meeting (see Appendix B), and poster boards and resource handouts for the survivors to provide them with education, empower them to make their own decisions, and guide them to takes steps independently (see Appendix C). The boards included steps to searching for jobs, building up their vocational skills, signing up for school for career building and learning English, and maintaining physical health and emotional health (with information on how trauma affects the brain to empower the clients to be proactive in their healing process). The deliverables were outlined in a way that educated both staff and clients to promote autonomy, and there was a focus on sustainability as the deliverables contained steps that can be followed independently.

The program was implemented throughout the next ten weeks while it was being developed. Some survivors were assisted in achieving their goals of achieving educational goals through guidance to proper resources and education on all their different options in this area, 
including how to research the pros and cons of each decision. The implementation for education participation was further developed to include research of majors and schools of interests, planning of courses and prerequisites, planning for transfer and graduate school, and signing up for classes. The area of engagement in employment acquisition was implemented by providing education and intervention on looking for open positions, filling out an application, and preparing for interviews. Another area of implementation included the process to learning English, signing up for courses, and having access to the resources necessary for everyday practice. The desired outcomes of these three areas included that the clients would achieve a sense of independence to initiate and organize their own procedures to achieve their goals, improved engagement and participation in decision-making for their occupation-based tasks, and a sense of readiness for further engagement with the community or satisfaction with the personal relationships they have built along the way during the process of the program. Further refinement of the program continued to be made throughout implementation to ensure sustainability of the program developed.

Resources for the staff were created to assist with reducing the risks of secondary traumatic stress (see Appendix B). Implementation of this resource allowed for two staff-led meetings, a month apart. The meeting brochure was outlined to provide directions for sustainable group sessions that are reflective and supportive between colleagues. The program provided education on compassion fatigue symptoms, risks, and interventions to promote accountability between staff. This resourced was decided to be necessary through result analysis as staff was expressing feelings of emotional fatigue, anxiety during interactions with clients, and implications were made on staff morale due to feeling overwhelmed. Staff identified areas where 
case management could be more effectiveness and assistance to the clients could be optimized if they can feel supported by a more cohesive and reflective environment.

\section{Chapter 5: Summary, Discussion, and Conclusion}

\section{Summary}

This capstone project was created to explore the areas occupational therapy can assist survivors of human trafficking for community reintegration. The project sought to understand the priorities of the survivors of human trafficking, their interests and goals, and occupation-based tasks that impact their daily sense of purpose and fulfillment. The project also sought to understand the obstacles that the survivors faced during their progression with occupational goals and independence. The staff of the community human trafficking organization contributed with their interpretation of the needs of the organization and the survivors in order to achieve effective case management outcomes when assisting their clients.

\section{Discussion}

The results were consistent with the themes found in the literature review. The clients of the community human trafficking organization had undergone immense traumatic experiences that increase their daily anxiety and feelings of helplessness when they cannot achieve their occupational goals. Trauma-informed care approaches were used during discussions with the clients as to not retrigger their experienced trauma, sensitivity and consideration were practiced by the student and staff of the organization during all conversations and interactions. Most clients reported that seeking vocation and education were their main priorities to achieve a sense of purpose and fulfillment, and lack of accomplishment in these areas was their source of anxiety. The clients who had stable income or a steady plan for their education achievement reported overall higher scores on all areas of the QOLS. The occupation-based findings in this 
capstone are consistent with the findings of the areas that affect the healing process of the survivors of human trafficking, as goal-setting and achievement of education and financial security were correlated to feelings of hope and character of resilience (Egger, 2017).

The staff of the human trafficking organization expressed feelings of being overwhelmed and reported symptoms of secondary traumatic stress. The results from the staff was unexpected from the capstone's original focus, but unsurprising due to the staff's consistent exposure to client trauma and coping mechanisms. Some clients expressed that their case manager was their "best friend" or the only person they could trust. The relationships were often overwhelming for the case managers, as some clients solely relied on their case managers to assist them with everyday tasks and decisions. The staff experienced a low sense of emotional support from each other, although they did not lack advice from upper-management on case management duties and barriers relating to their responsibilities. Education was necessary for both client and staff emotional health to promote autonomy in the healing process and encourage healthy coping mechanisms.

\section{Implications for Occupational Therapy}

Occupational therapy has a continued role in assisting survivors of human trafficking in their transition to community reintegration. OT can address occupation-based tasks prioritized by the survivors that impact their sense of purpose and fulfillment. Education and assistance with organization can promote occupational independence and autonomy as the survivors progress further in their process of transition. Occupational therapy also has a role in addressing the barriers that the clients and staff face to achieving their occupational goals, including environmental barriers, emotional health, physical health, and lack of knowledge on processes required to perform their desired tasks. 
Continued effectiveness of the occupation-based program and the resources given to clients and staff by using a survey and suggested areas to measure include: successfulness in ability to perform occupational tasks, readiness to independently initiate occupational tasks, satisfaction levels with occupational tasks (such as using the COPM or QOLS) ability to reach daily occupational goals, feelings of cohesiveness between staff and clients, and feelings of connectivity to society and the local community. Suggested areas to survey the staff include: satisfaction with work performance, satisfaction with daily occupational goals, feelings of achievement in helping clients achieve their goals, feelings of helplessness in their work duties, and identification of supportiveness from other members of staff. Effectiveness can be gathered by scoring the data at before and after they follow steps to achieve their occupational goals during their resources, which can take roughly between 8 to 24 weeks.

\section{Conclusion}

Survivors of human trafficking experienced traumatic events that affect them emotionally, cognitively, and physically. During their time as victims, they had a lack of autonomy which affects their independence with occupational tasks as they transition to community reintegration as a survivor. This capstone explored the priorities of the survivors, their occupational barriers, and the priorities and barriers of the staff who interact daily with the survivors throughout their process of transition. Program implementation and development provided education and assistant to the participants, which included both staff and survivors, to achieve their occupational goals through independence and autonomy regarding their choices and procedural steps. 


\section{References}

Adams Hillard, P. J. (2019). Why and how to perform trauma-informed care. Contemporary $O B / G Y N, 64(8), 15-16$.

https://search.proquest.com/docview/2315019116?accountid=158603

American Occupational Therapy Association. (2014-a). Occupational therapy practice

framework: Domain and process (3rd ed.). American Journal of Occupational Therapy, 68(Suppl.1), S1-S48. https://doi.org/10.5014/ajot.2014.682006

American Occupational Therapy Association. (2014-b). Scope of Practice. American Journal of Occupational Therapy, 68(Suppl.3), S34-S40. https://doi.org/10.5014/ajot.2014.686S04

American Occupational Therapy Association. (2017). Vision 2025. American Journal of Occupational Therapy, 71, 7103420010. https://doi.org/10.5014/ajot.2017.713002

American Occupational Therapy Association. (2018). AOTA's societal statement on stress, trauma, and posttraumatic stress disorder. American Journal of Occupational Therapy, 72(Suppl.2), 7212410080. https://doi.org/10.5014/ajot.2018.72S208

Black, J. G. (2007). Human trafficking: Common diagnoses and the treatment of sexual exploitation [Doctoral dissertation]. Available from ProQuest Dissertations. (UMI Number: 3313086)

Cerny, S. (2016). The role of occupational therapy within the Federal Strategic Action Plan on services for victims of human trafficking in the United States. Occupational Therapy in Mental Health, 32(4), 317-328, https://doi.org/10.1080/0164212X.2016.1172998

Christiansen, C. H. (1999). Defining lives: Occupation as identity: An essay on competence, coherence and the creation of meaning. American Journal of Occupational Therapy, 53, 547-558. https://doi.org/10.5014/ajot.53.6.547 
Connor, J. N. (2019 April 22). Fostering independence is what occupational therapy is all about. Sheppard Pratt. https://www.sheppardpratt.org/news-views/story/fosteringindependence-is-what-occupational-therapy-is-all-about/

Durocher, E., Gibson, B. E., \& Rappolt, S. (2013). Occupational justice: A conceptual review. Journal of Occupational Science, 21(4), 418-430.

https://doi.org/10.1080/14427591.2013.775692

Dunn, W., Brown, C., \& McGuigan, A. (1994). The Ecology of Human Performance: A framework for considering the effect of context. American Journal of Occupational Therapy, 48(7), 595-607. https://doi.org/10.5014/ajot.48.7.595

Egger, A. (2017). Human sex trafficking: How sex trafficking victims and survivors experience hope and resilience [Doctoral dissertation]. Available from ProQuest Dissertations. (ProQuest Number: 10629214)

Forsyth, C. M. (2016). The impact of vicarious traumatization on lay counselors working with survivors of human trafficking in the Philippines [Capstone]. Azusa Pacific University. Available from ProQuest Dissertations. (UMI Number: 10113165)

George, E. \& Stanley, M. (2018): Exploring the occupational injustices of human trafficking. Journal of Occupational Science. https://doi.org/10.1080/14427591.2018.1515104

Ginsberg, K. (2015). The 7 Cs: The essential building blocks of resilience. Retrieved from http://fosteringresilience.com/professionals/7cs_professionals.php

Goodey, J. (2004). Sex trafficking in women from Central and East European countries: promoting a 'victim-centred' and 'woman-centred' approach to criminal justice intervention. Feminist Review, 76. https://doi.org/10.1057/palgrave.fr.9400141 
Gorman, K. W., \& Hatkevich, B. A. (2016). Role of occupational therapy in combating human trafficking. The American Journal of Occupational Therapy, 70(6), 1-6. https://doi.org/10.5014/ajot.2016.016782

Harding-Jones, C. (2018). Counseling sex-trafficked clients using trauma-focused cognitive behavioral therapy. Healthcare Counselling \& Psychotherapy Journal, 18(2), 14750724.

Harding-Jones, C. (2019). Counselling survivors of sex trafficking: Cate Harding-Jones describes the challenges of working as part of a team in a safe house for women who have escaped sexual slavery. Therapy Today, 30(1), 20-24. http://search.ebscohost.com.prx-usa.lirn.net

Harriot, S. (2017). Overcoming barriers to services for domestic adult female sex trafficking victims in Georgia [Doctoral dissertation]. Available from ProQuest Dissertations. (ProQuest Number: 10603532)

International Labour Organization. (2014a). Profits and poverty: The economics of forced labour. https://www.ilo.org/wcmsp5/groups/public/---ed_norm/--declaration/documents/publication/wcms_243391.pdf

International Labour Organization. (2014b May 20). ILO says forced labour generates annual profits of US \$150 billion. ILO Newsroom: Economics of Forced Labour. http://www.ilo.org/global/about-the-ilo/newsroom/news/WCMS_243201/lang-en/index.htm

International Labour Organization. (2017 September). Forced labour, modern slavery and human trafficking. http://www.ilo.org/global/topics/forced-labour/lang--en/index.htm

Kielhofner, G. (2008). Model of Human Occupation Theory and Application (4th ed.). Lippincott Williams \& Wilkins. 
Kliner, M. \& Stroud, L. (2012). Psychological and health impact of working with victims of sex trafficking. Journal of Occupational Health, 54(1), 9-15. https://doi.org/10.1539/joh.110125-oa

Levine, J. A. (2017). Mental health issues in survivors of sex trafficking. Cogent Medicine, 4(1). https://doi.org/10.1080/2331205X.2017.1278841

Lewis, S. D., Henriksen, R. C., \& Watts, R. E. (2015). Intimate partner violence: The recovery experience. Women \& Therapy, 38(3-4), 377-394. https://doi.org/10.1080/02703149.2015.1059223

Macias Konstantopoulos, W., Ahn, R., Alpert, E. J., Cafferty, E., Mcgahan, A., Williams, T. P., Castor, J. P., Wolferstan, N., Purcell, G., \& Burke, T. F. (2013). An international comparative public health analysis of sex trafficking of women and girls in eight cities: Achieving a more effective health sector response. Journal of Urban Health, 90(6), 11941204. https://doi.org/10.1007/s11524-013-9837-4

Mariano, M. (2019). The role of occupational therapy for survivors of human trafficking [Capstone]. University of St. Augustine. Retrieved from https://soar.usa.edu/capstones/8

Martin, E. (2015). Trauma-informed programming: Occupation-based groups for adolescent sex trafficking survivors [Capstone]. Pacific University. http://commons.pacificu.edu/otde/4

Menschner, C. \& Maul, A. (2016 April). Key ingredients for successful trauma-informed care implementation. Center for Health Care Strategies. https://www.chcs.org/resource/keyingredients-for-successful-trauma-informed-care-implementation/

Morey, R. A., Dolvos, F., Petty, C. M., Cooper, D. A., Hayes, J. P., LaBar, K. S., \& McCarthy, G. The role of trauma-related distractors on neural systems for working memory and 
emotiona processing in posttraumatic stress disorder. Journal of Psychiatric Research, 43(8), 809-817. https://doi.org/10.1016/j.jpsychires.2008.10.014

National Child Traumatic Stress Network, Secondary Traumatic Stress Committee. (2011).

Secondary traumatic stress: A fact sheet for child-serving professionals. Los Angeles, CA, and Durham, NC: National Center for Child Traumatic Stress.

https://www.nctsn.org/sites/default/files/resources/fact-

sheet/secondary_traumatic_stress_child_serving_professionals.pdf

National Human Trafficking Hotline. (n.d.). Labor trafficking.

https://humantraffickinghotline.org/es/type-trafficking/labor-trafficking?qt-

stats_issues $=3 \&$ page $=1$

Oram, S. \& Domoney, J. (2018). Responding to the mental health needs of trafficked women.

Healthcare Counselling and Psychotherapy Journal, 18(2).

https://www.bacp.co.uk/bacp-journals/healthcare-counselling-and-psychotherapyjournal/april-2018/responding-to-the-mental-health-needs-of-trafficked-women/

Paul-Ward, A. (2009). Social and occupational justice barriers in the transition from foster care to independent adulthood. American Journal of Occupational Therapy, 63, 81-88.

Perry, B. D., Pollard, R. A., Blaicley, T. L., Baker, W. L., \& Vigilante, D. (1995). Childhood trauma, the neurobiology of adaptation, and "Use-dependent" development of the brain: How "States" become "Traits." Infant Mental Health Journal, 16(4), 271-291. https://doi.org/10.1002/1097-0355(199524)16:4<271::AID-IMHJ2280160404>3.0.CO;2B 
Phelan, S., \& Kinsella, E. A. (2009). Occupational identity: Engaging socio-cultural perspectives. Journal of Occupational Science, 16(2), 85-91. https://doi.org/10.1080/14427591.2009.9686647

Polaris. (2019 July 31). 2018 statistics from the National Human Trafficking Hotline. Polaris Project. https://polarisproject.org/wpcontent/uploads/2019/09/Polaris_National_Hotline_2018_Statistics_Fact_Sheet.pdf

Ramafikeng, M. (2011). Lecture: Ecology of Human Performance. Retrieved from https://vula.uct.ac.za/access/content/group/9c29ba04-b1ee-49b9-8c859a468b556ce2/Framework_2/pdf/The\%20ecology\%20of\%20human\%20performance.pdf

Rape, Abuse \& Incest National Network (RAINN), Alexenko, N., Satinsky, J., \& Simmons, M. (n.d.). Victim or survivor: Terminology from investigation through prosecution. Sexual Assault Kit Initiative, 1-2. https://sakitta.org/toolkit/docs/Victim-or-SurvivorTerminology-from-Investigation-Through-Prosecution.pdf

Rauvola, R. S., Lavigne, K. N., \& Vega, D. M. (2017). Compassion fatigue, secondary traumatic stress, and vicarious traumatization: A qualitative review and research agenda. Occupational Health Science. https://doi.org/ DOI: 10.1007/s41542-019-00045-1

Riopel, L. (2019). 5 Quality of life questionnaires and assessments. Positive Psychology. https://positivepsychology.com/quality-of-life-questionnaires-assessments/

Russell, C., Fitzgerald, M. H., Williamson, P., Manor, D., \& Whybrow, S. (2002). Independence as a practice issue in occupational therapy: The safety clause. American Journal of Occupational Therapy, 56(4), 369-379. https://doi.org/10.5014/ajot.56.4.369 
Sacheti, A. (2020). Emotional experiences of mental health providers who have worked with survivors of human trafficking: A qualitative study [Capstone]. Alliant International University. Available from ProQuest Dissertations. (UMI Number: 27998316)

Stewart, K. E., Mont, J. D., Polatajko, H. J. (2019). Applying an occupational perspective to women's experiences of life after sexual assault: A narrative review. Journal of Occupational Science, 26(4), 546-558. https://doi.org/10/1080/14427591.2018.1516159

Sukach, T., Castañeda, N. G., Pickens, J. C. (2018). Experiences of female sex trafficking survivors: A phenomenological analysis. The Qualitative Report, 23(6), 1422-1440. https://nsuworks.nova.edu/tqr/vol23/iss6/10/

Thompson, T. (2017). Community living integration club for women in recovery from sex trafficking [Capstone]. Nova Southeastern University. Retrieved from NSUWorks, College of Health Care Sciences - Occupational Therapy Department. (47). https://nsuworks.nova.edu/hpd_ot_student_dissertations/47

United Nations Office on Drugs and Crime. (2015). Issue paper: the concept of 'exploitation' in the trafficking in persons protocol. https://www.unodc.org

Wilson, B., \& Butler, L. D. (2014). Running a gauntlet: A review of victimization and violence in the pre-entry, and peri-/post-exit periods of commercial sexual exploitation. Psychological Trauma: Theory, Research, Practice, and Policy, 6(5), 494-504. https://doi.org/10.1037/a0032977 


\section{Appendix A - Quality of Life Scale}

\section{QUALITY OF LIFE SCALE (QOL)}

Please read each item and circle the number that best describes how satisfied you are at this time. Please answer each item even if you do not currently participate in an activity or have a relationship. You can be satisfied or dissatisfied with not doing the activity or having the relationship.

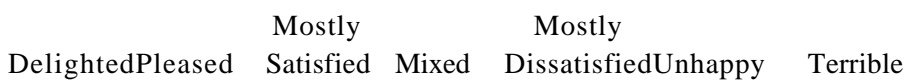

financial security . . . . . . . . . . . . .

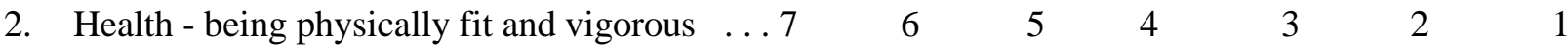

3. Relationships with parents, siblings \& other

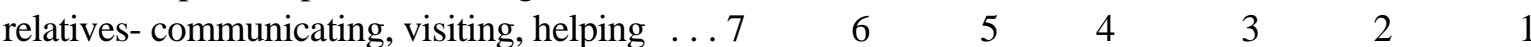

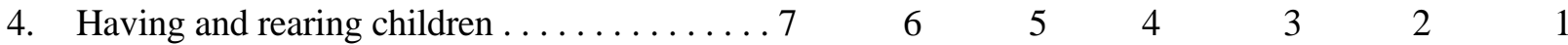

5. Close relationships with spouse or significant other................

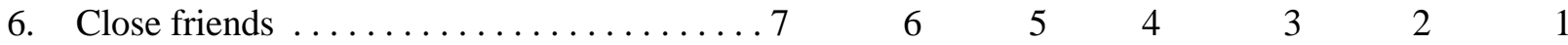

7. Helping and encouraging others,

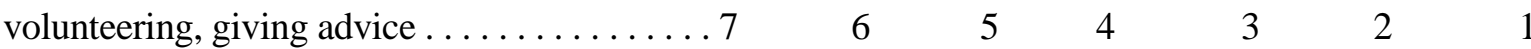

8. Participating in organizations and public affairs ...................

9. Learning- attending school, improving understanding, getting additional knowledge . .

10. Understanding yourself - knowing your assets and limitations - knowing what life is about . . 7

11. Work - job or in home .............

12. Expressing yourself creatively $\ldots \ldots \ldots \ldots$

13. Socializing - meeting other people, doing things, parties, etc . . . . . . . . . .

14. Reading, listening to music, or observing entertainment . . . . . . . . . . . .

15. Participating in active recreation $\ldots \ldots \ldots \ldots 7$

16. Independence, doing for yourself $\ldots \ldots \ldots 7$

$\begin{array}{llllll}6 & 5 & 4 & 3 & 2 & 1\end{array}$

Burakhardt, C. S. (n.d.). Instructions for scoring the Quality of Life Scale. Oregon Health Sciences University. http://www.contentedits.com/img.asp?id=13179 


\section{Appendix B - Deliverables for Staff}

\section{Peogram Peflection Mecting}

Purpose

The purpose of this meeting is to create a therapeutic time for the staff to encourage and support one another to reduce the risks and symptoms of compassion fatigue. All participants should be focused on sharing their reflection of BSCC. The environment should remain positive, constructive, and encouraging through positive feedback and suggestions for improvement. The meeting is to remain program-focused to reduce tangential discussions. Having a plan for self-care amongst the staff can improve resiliency and motivation.

\section{Do}

- Hold these meetings once a month, or more often as needed by BSCC staff

- Give thanks, express gratitude, highlight the strengths of the program and the performance of colleagues

- Keep it positive, give only constructive suggestions

- Wait for everyone to share before responding or making comments

I. Choose a meeting facilitator.

2. The meeting should last roughly one hour.

3. Everyone writes their thoughts on the paper for each category (Encouragement \& Constructive Feedback).

a. Please try to write at least one encouragement to share with the group, the constructive feedback is optional but welcomed.

4. Take turns sharing what was written, consider going in a circle or popcorn.

5. Open space for comments or feedback between all staff.
Don't

- Speak about case-management topics - Criticize, share negativity, or complain 


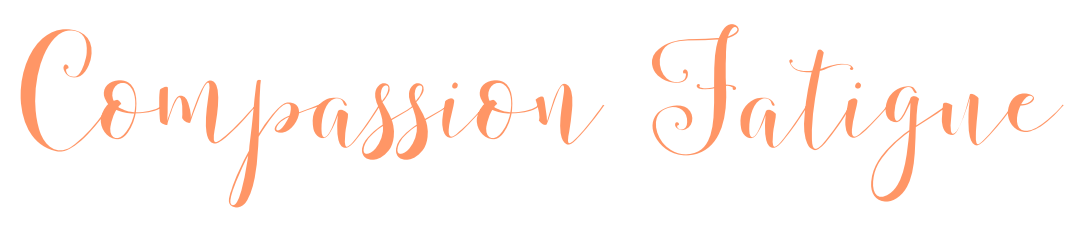

\section{Why is this meeting necessary?}

The staff members of BSCC are direct caregivers and supporters for survivors of human trafficking. The clients served have undergone multiple traumatic experiences and require sensitivity to their experiences, including a trauma-informed approach. Under this environment, BSCC staff may experience symptoms of caretaker burn-out, also known as secondary traumatic stress, compassion fatigue, or empathy-based stress. It is not uncommon for staff members in a trauma-related line of work to feel overwhelmed, resulting in occupational health reactions and well-being outcomes. Unattended outcomes of compassion fatigue can affect work productivity and the quality of care offered to the clients.

\section{Risks of compassion fatigue include:}

- Personal engagement with the clients' traumatic stories

- Neglect of self-care in the midst of helping clients

- Personal exposure to clients' traumatic events or their way of coping and reacting to their trauma

- Large caseload or imbalanced work hours

- Lack of professional training

\section{Management}

of compassion fatigue includes awareness and early detection. An organization can share information about the risks to their staff and take measures to decrease the risks. Regular small group check-ins with one another are essential to providing a supportive environment.

\section{The symptoms of compassion} fatigue can include, but are not limited to:

- Emotional: feeling numb, detached, overwhelmed, hopeless, or irritable - Physical: having low energy, sleeping and eating difficulty

- Behavioral: changing routine or engaging in self-destructive coping mechanisms - Professional: experiencing impaired competence, or having low job morale - Cognitive: experiencing confusion, low concentration, difficulty with decision making, or traumatic imagery

- Spiritual: questioning personal satisfaction with life, or the purpose of life - Interpersonal: withdrawing from friends and family or becoming emotionally unavailable to co-workers and close relationships

Individuals can protect themselves by practicing self-care through exercise, keeping a healthy diet, and sufficient sleep. Meditative activities, self-reflection, and active movements can help reduce stress and anxiety.

It is essential that staff take breaks from stressful situations at work and spend time with their family, friends, or special interests. A counselor may provide coping strategies appropriate for the staff member experiencing secondary traumatic stress. 


\section{Encouragement}

Constructive Feedback

Encouragement

Constructive Feedback

Encouragement

Constructive Feedback 


\section{Appendix C - Deliverables for Clients}

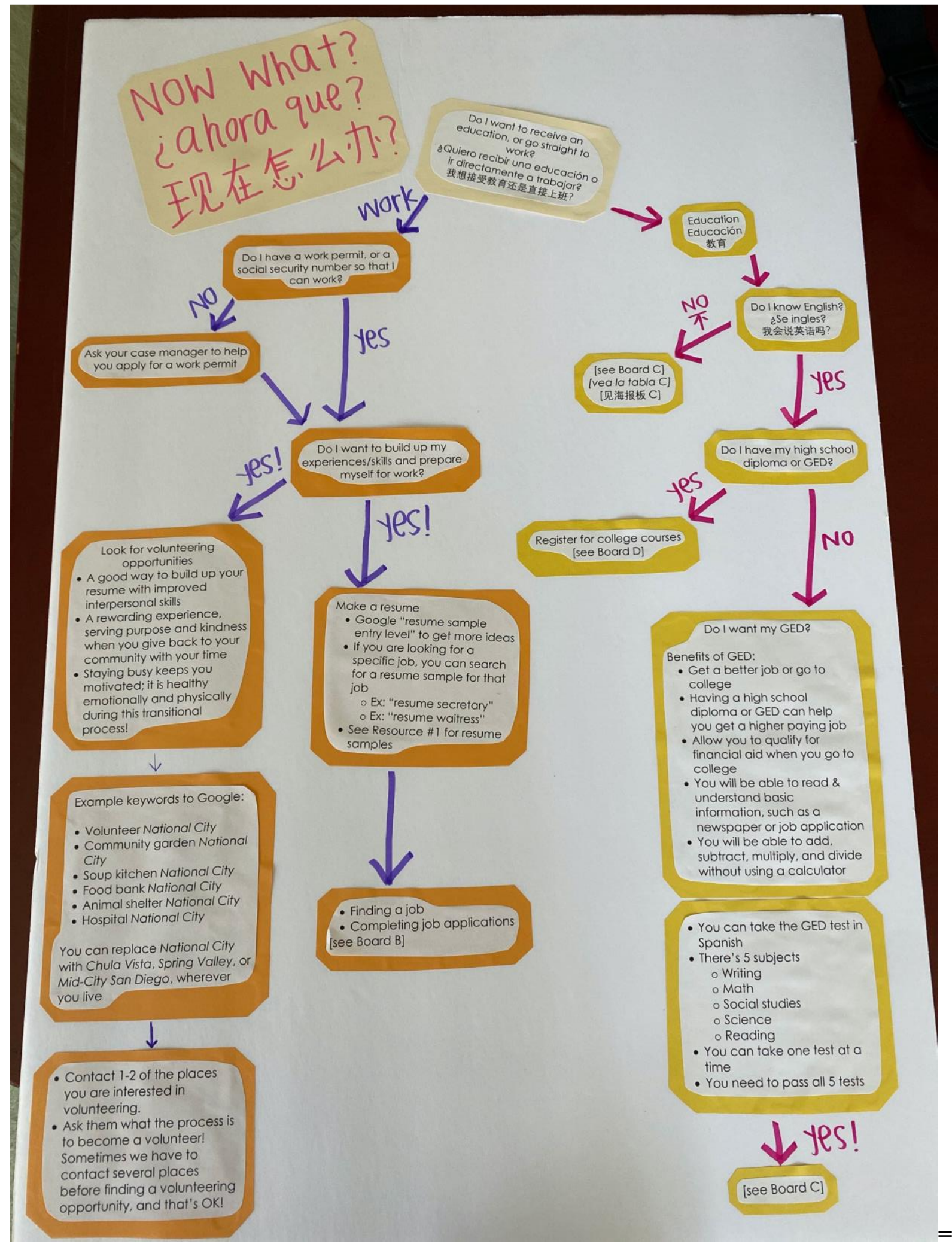




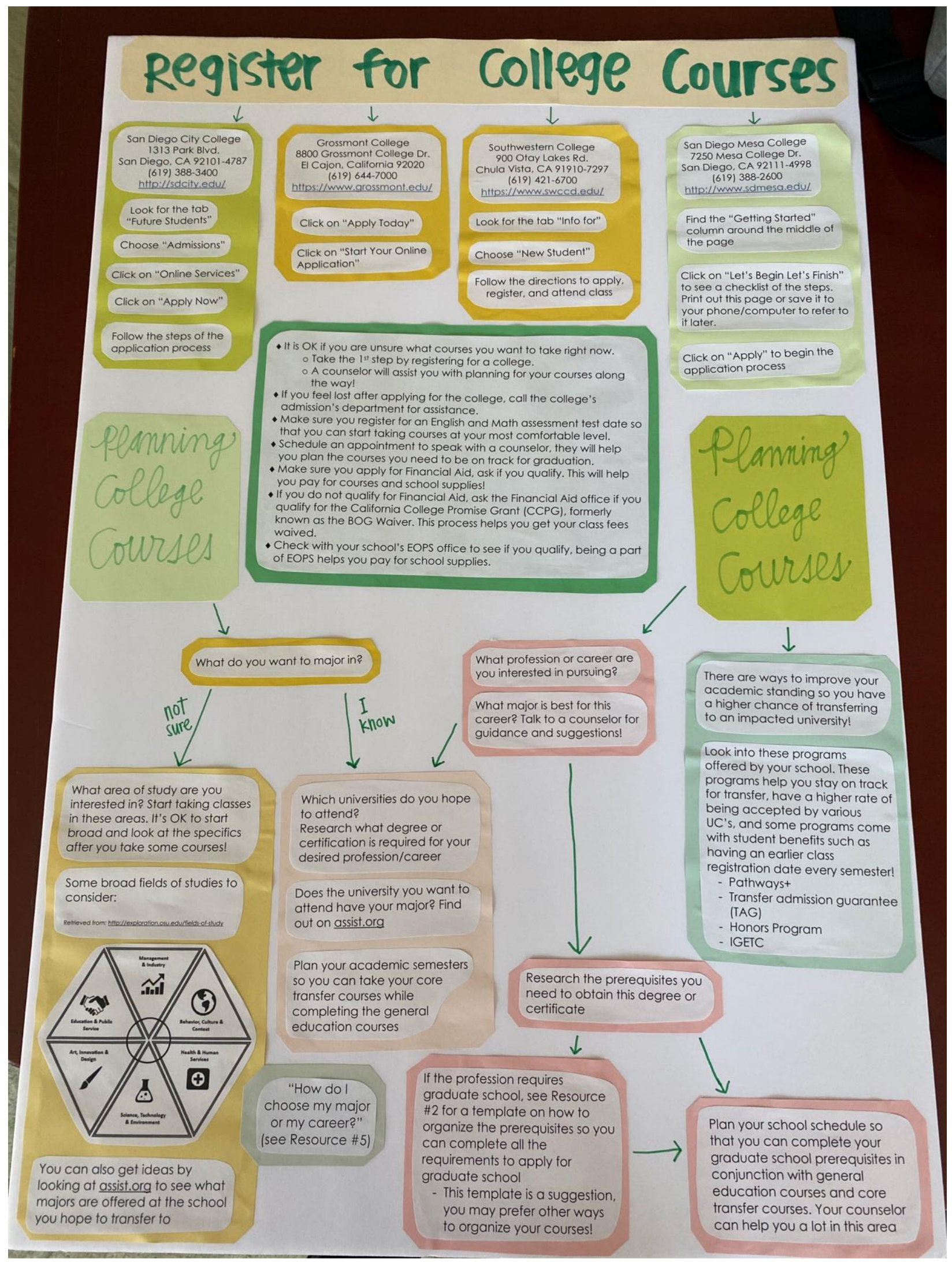




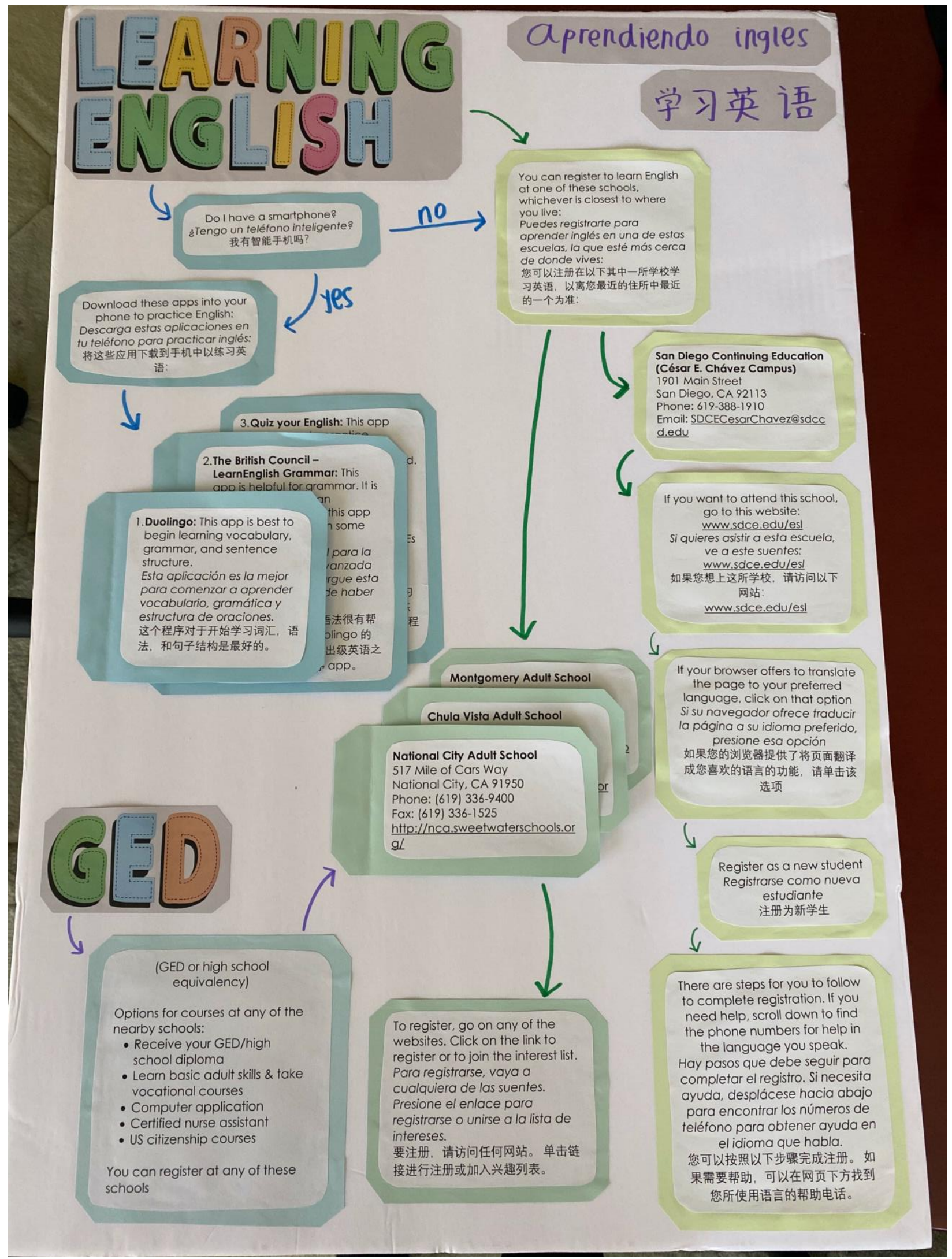




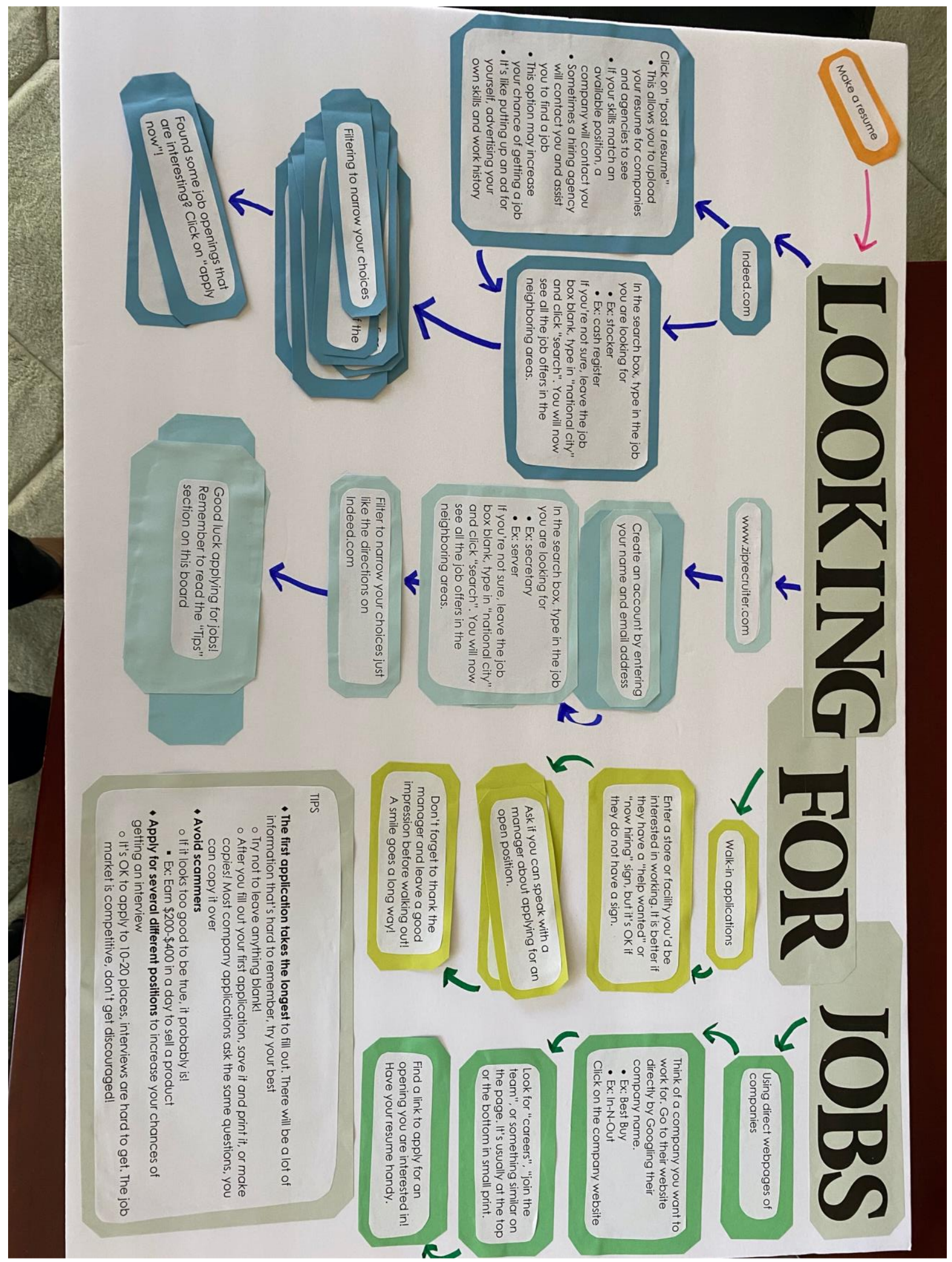




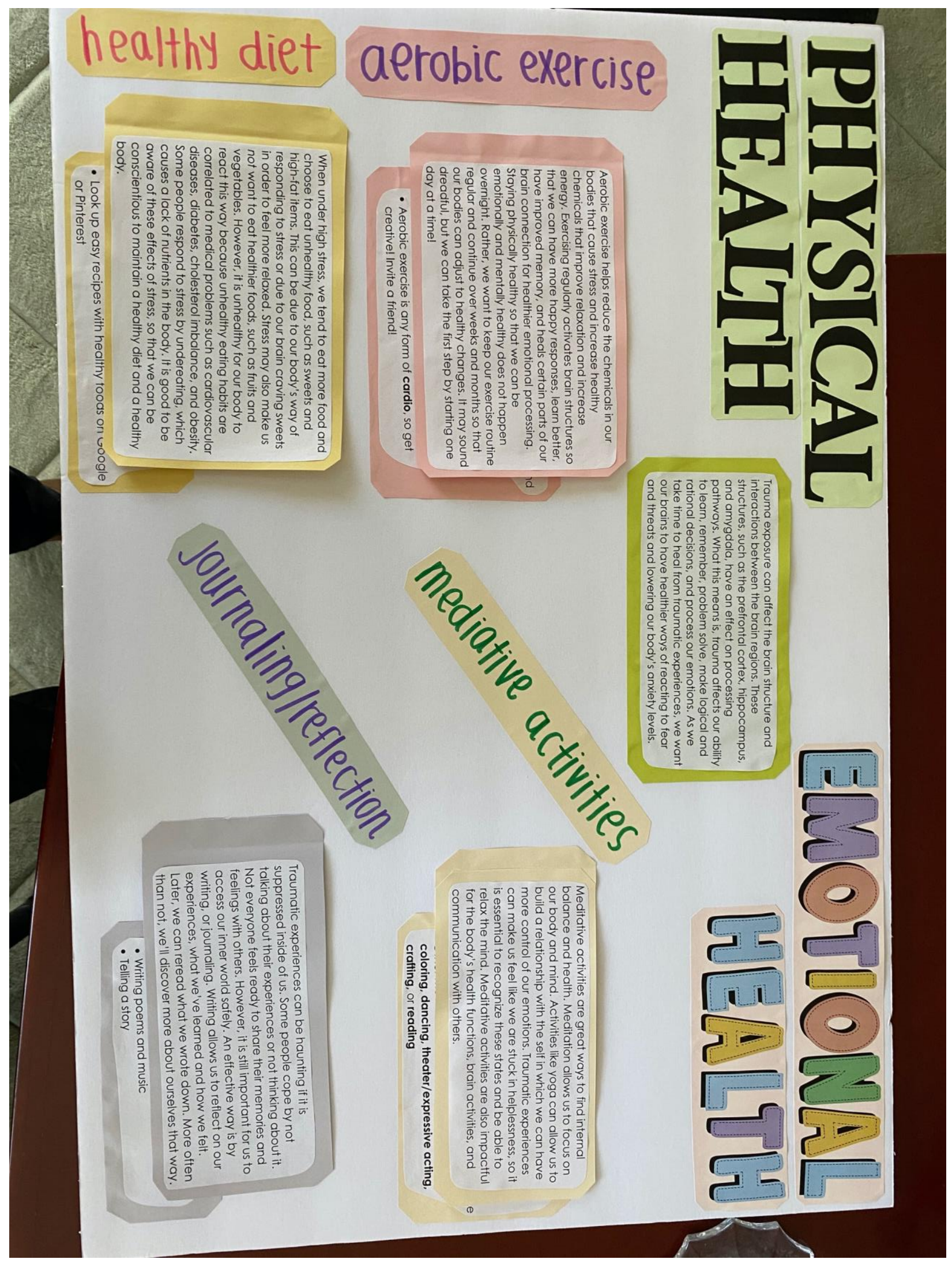




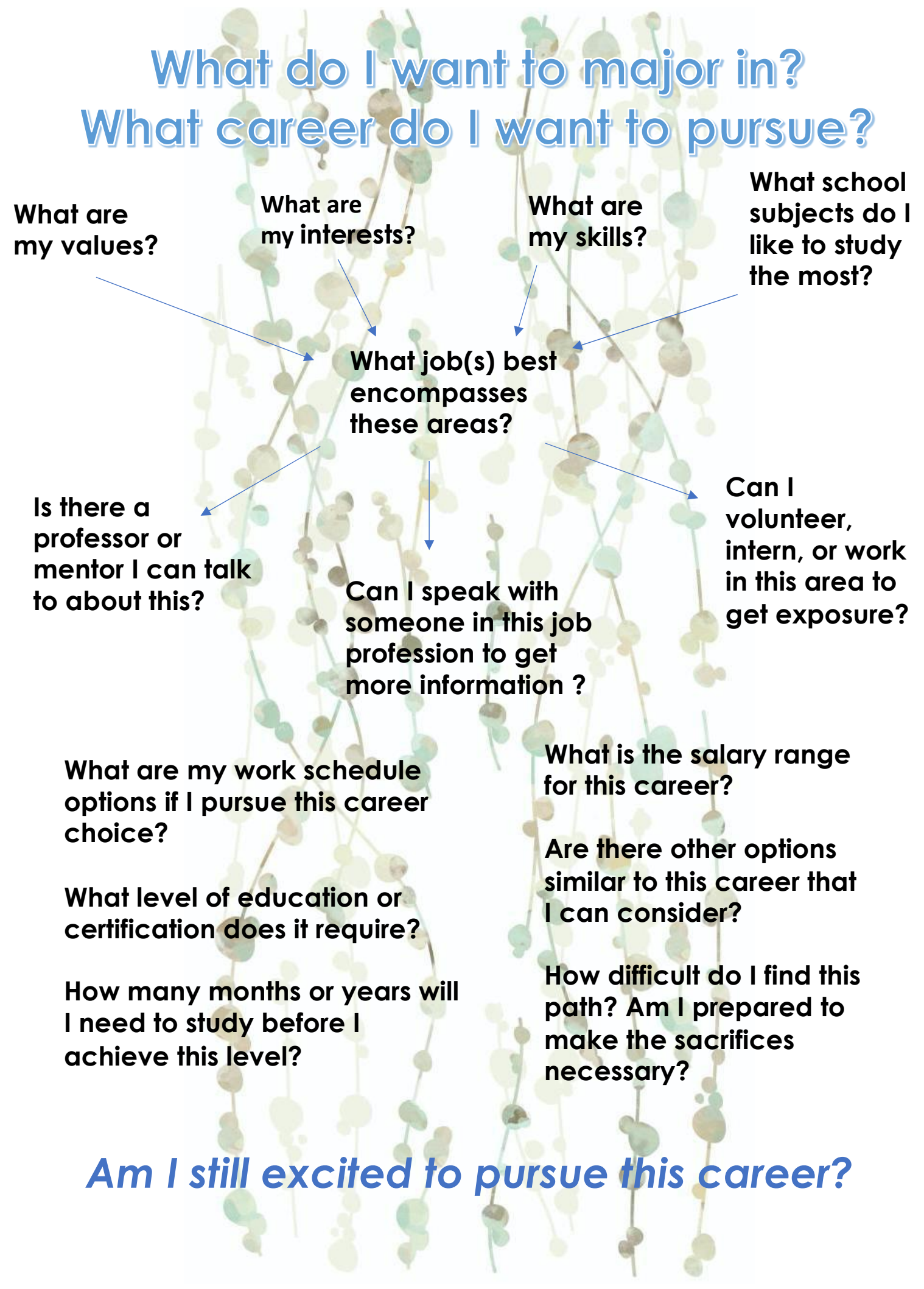




\begin{tabular}{|c|c|c|c|}
\hline & [Graduate School Name] & example: UC Davis & example: Cal State San Marcos \\
\hline Prerequisite & $\begin{array}{l}\text { [minimum GPA required, time length before } \\
\text { courses are expired, mininum grade per course] }\end{array}$ & $\begin{array}{c}\text { example: } 3.0 \text { GPA, courses within } 10 \text { years, C or } \\
\text { higher }\end{array}$ & $\begin{array}{l}\text { [minimum GPA required, time length before } \\
\text { courses are expired, mininum grade per course] }\end{array}$ \\
\hline \multicolumn{4}{|l|}{ Core course requirements } \\
\hline \multicolumn{4}{|l|}{ example: General Biology I } \\
\hline \multicolumn{4}{|l|}{ example: Physics w/ Calculus I } \\
\hline & & & \\
\hline & & & \\
\hline & & & \\
\hline \multicolumn{4}{|l|}{ General course requirements } \\
\hline \multicolumn{4}{|l|}{ example: English Composition } \\
\hline & & & \\
\hline \multicolumn{4}{|l|}{ Special course requirements } \\
\hline \multicolumn{4}{|l|}{ example: Medical Ethics } \\
\hline \multicolumn{4}{|l|}{ example: 3-D art } \\
\hline \multicolumn{4}{|l|}{ example: Spanish } \\
\hline \multicolumn{4}{|l|}{ Other requirements } \\
\hline \multicolumn{4}{|l|}{ GRE, MCAT, PCAT, LSAT } \\
\hline \multirow{2}{*}{\multicolumn{4}{|c|}{ Lefters of recommendation }} \\
\hline \multirow{2}{*}{\multicolumn{4}{|c|}{ Clinical hours }} \\
\hline \multicolumn{2}{|l|}{ Shadowing hours } & & \\
\hline \multicolumn{4}{|l|}{ Community Service Activities } \\
\hline \multicolumn{4}{|l|}{ Personal statement/Narrative essay } \\
\hline Completed & & & \\
\hline In progess & & & \\
\hline Needed & & & \\
\hline
\end{tabular}




\section{Appendix D - Logic Model}

Program: Human Trafficking Survivors using Occupation-Based program for Community Reintegration Logic Model

Situation: Survivors of human trafficking are facing a variety of barriers that inhibit their ability to reintegrate into the community and obtain occupational independence. This program seeks to implement a program based on their needs and goals reported by the survivors themselves during needs assessment, which includes finding a job and receiving education.

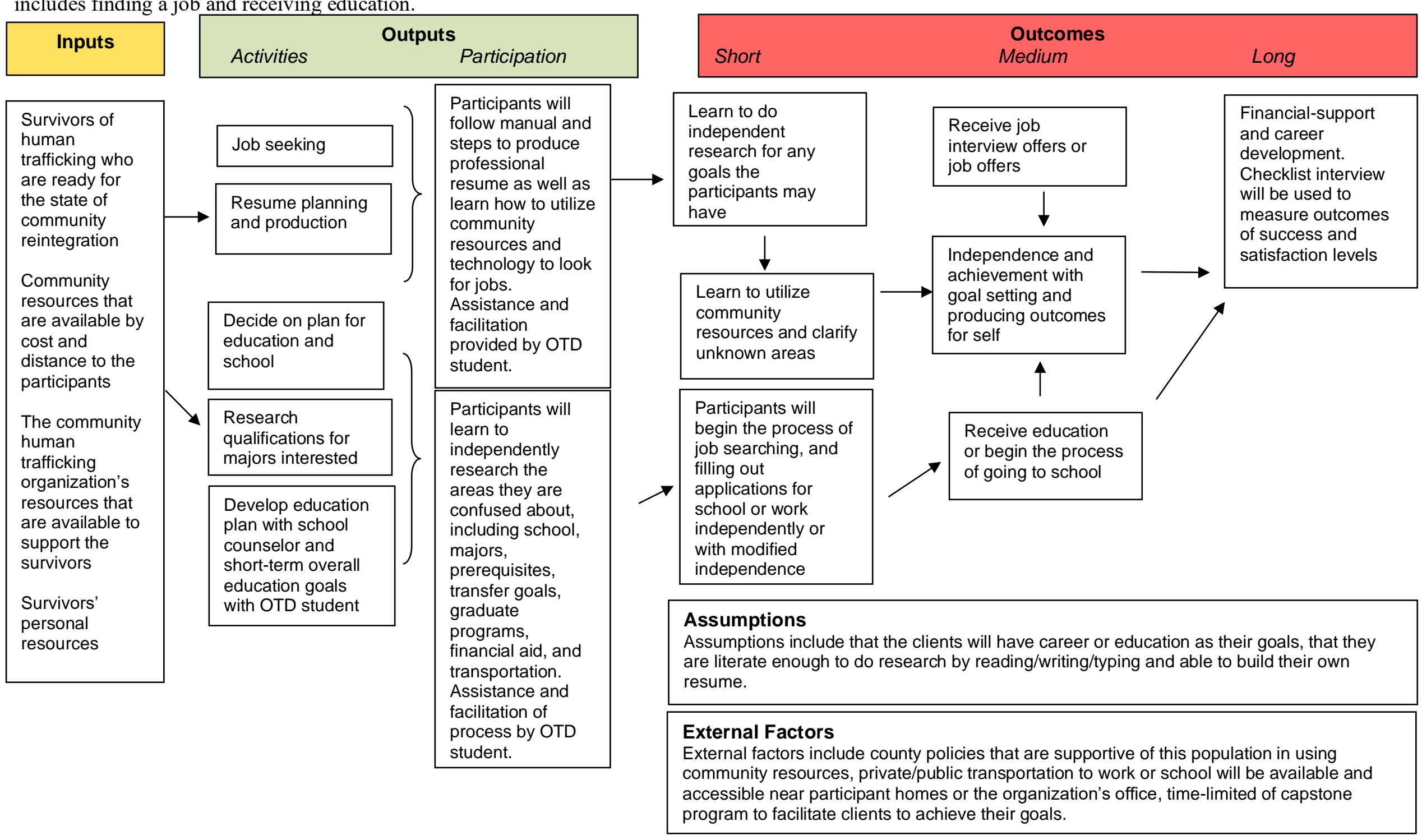


